\title{
Preliminary Study on Hepatoprotective Activity of Aqueous Crude Extract of Allium ascalonicum against Ethanol-induced Liver Injury in Mice $^{\dagger}$
}

\author{
Sakaewan OUNJAIJEAN ${ }^{1}$ and Voravuth SOMSAK ${ }^{2, *}$ \\ ${ }^{1}$ School of Health Science Research, Research Institute for Health Sciences, Chiang Mai University, \\ Chiang Mai 50200, Thailand \\ ${ }^{2}$ School of Allied Health Sciences, Walailak University, Nakhon Si Thammarat 80161, Thailand
}

('Corresponding author's e-mail: voravuth.so@wu.ac.th)

Received: 3 April 2019, Revised: 5 July 2019, Accepted: 18 August 2019

\begin{abstract}
Ethanol-induced liver injury is an aggravated liver disease with a diverse spectrum from steatosis to hepatitis, fibrosis, and cirrhosis. Epidemiological studies reveal that ethanol-induced liver injury has become one of the most intense threats to global health. Therefore, this study investigated the hepatoprotective property of Allium ascalonicum extract against ethanol-induced liver injury in mice. Aqueous crude extract of $A$. ascalonicum bulbs was prepared, and acute toxicity was, then, carried out in mice. The results indicated that $A$. ascalonicum extract at the dose up to $2,000 \mathrm{mg} / \mathrm{kg} / \mathrm{day}$ did not cause mortality and liver injury as indicated by non-significant differences in AST, ALT, GGT, and ALP levels, compared to healthy control within the monitoring period. For in vivo efficacy test, the experimental mice were orally administered with $50 \%(\mathrm{v} / \mathrm{v})$ ethanol for 14 consecutive days, then further treated with the extract $(50,100$, and $200 \mathrm{mg} / \mathrm{kg}$ ) once a day for another 7 consecutive days. Significant, dose-dependent decrease of AST, ALT, GGT, and ALP levels was observed in ethanol-induced liver injury mice treated with $A$. ascalonicum extract. The present study clearly demonstrated that the aqueous crude extract of $A$. ascalonicum bulbs exert a hepatoprotective effect against ethanol-induced liver injury in the mice model. A. ascalonicum extract might be a promising remedy to treat alcoholic liver disease.
\end{abstract}

Keywords: Hepatoprotective, Allium ascalonicum, Ethanol-induced liver injury

\section{Introduction}

Due to drinking behavior and alcohol abuse, the morbidity and mortality of alcoholic liver disease are increasing in the world today. Approximately 3.3 million people die annually from the overconsumption of ethanol, and it can also lead to many metabolic diseases [1]. In Thailand, the health costs of alcohol consumption was estimated at about US\$5 billion in 2006, representing $2 \%$ of GDP [2]. With the loss of $5.3 \%$ of disability adjusted life years attributed to its consumption, alcohol is now the $3^{\text {rd }}$ most significant health risk for Thai men [3]. Alcohol consumption was also associated with increased risks for non-communicable diseases outcomes, for example, hypercholesterolemia, hypertension, and liver diseases [4]. In the present, oxidative stress and inflammation are considered to be the 2 major mechanisms involved in the pathogenesis of ethanol-induced liver injury [5-8]. Three pathologically lifethreatening liver diseases induced by ethanol abuse are fatty liver (steatosis), hepatitis, and cirrhosis [9]. Currently, some antioxidant and anti-inflammatory drugs such as glutathione, corticosteroids, colchicine,

\footnotetext{
${ }^{\dagger}$ Presented at the International Conferences on Biomedical Sciences and Medical Technology 2019: June 20 - 21, 2019
} 
and S-adenosyl methionine have been use for treatment in patients with ethanol-induced liver injury. However, these drug treatments are accompanied by the side effects, such as jaundice and kidney impairment [10]. In this respect, herbal plant extracts and their active ingredients are potential targets as new drugs against ethanol-induced liver injury due to their potent efficiency, safety, and relative low costs [11-13]. Allium ascalonicum (shallot) is 1 of the most important agricultural product in Thailand, especially in the North and Northeast areas [14]. The major activities of A. ascalonicum are believed to be mediated via redox-dependent mechanisms and numerous pharmacological properties including antioxidant, anti-inflammation, anti-microbials, anti-cancer, anti-hyperglycemia, and protective effects on several vital organs [15-19]. The plant elements include various phytochemicals and phytonutrients, such as flavonoid glycosides including quercetin and allicin [20]. It has been reported that the biological properties of Allium sativum (garlic) confer hepatoprotection on ethanol-induced hepatotoxicity [21]. However, there is no report yet on the protective activity of $A$. ascalonicum against ethanol-induced liver injury. Hence, this present study investigates the hepatoprotective activity of $A$. ascalonicum extract against ethanol-induced liver injury in mice.

\section{Materials and methods}

\section{Chemicals}

Silymarin and ethanol were obtained from Sigma-Aldrich (St. Louis, MO, USA). All reagents were of analytical grade. The chosen doses of silymarin were prepared in distilled water (DW).

\section{Preparation of aqueous crude extract}

Fresh bulbs of $A$. ascalonicum were purchased from the local market at Suphanburi province, Thailand. The plant bulbs were peeled, washed, and cut into small pieces. The juice was subsequently prepared by blending the bulbs in distilled water (DW) at the ratio of 1:10 in an electric blender for 5 min, and incubated at room temperature for $72 \mathrm{~h}$. The filtrate was, then, collected by filtering through gauze, and lyophilization was subsequently carried out to obtain dried crude extract powder. The extract was stored at $-20^{\circ} \mathrm{C}$ until further usage.

\section{Experimental mice}

Pathogen-free, male ICR (Imprinting Control Region) mice (6 - 8 weeks old, 25 - 30 g) purchased from the National Laboratory Animal Center, Mahidol University, Thailand were used in this study. They were kept in the animal room at a temperature range of $22-25^{\circ} \mathrm{C}, 12 \mathrm{~h}$ light-dark cycle, and were given a standard diet pellet CP082 and clean water ad libitum. All experiments involving animal were ratified and approved by the Animal Ethic Committee, Western University (WTU-AEC-002/2018).

\section{Acute toxicity test of $A$. ascalonicum extract}

The acute toxicity test of the extract in mice was carried out by using the method previously described [22]. Experimental mice $(5$ mice) were administered orally by gavage with a single dose of $2,000 \mathrm{mg} / \mathrm{kg}$ of the extract once a day for 7 consecutive days. The mice were observed for signs of toxicity (paw licking, salivation, stretching of the entire body, weakness, respiratory distress, coma, and death) in the first four hours and subsequently daily for further 14 days. Lastly, mouse blood was collected by cardiac puncture for liver function test.

\section{Efficacy test of $\boldsymbol{A}$. ascalonicum extract in mice}

Experimental mice were divided into 6 groups ( 5 mice per group). Group 1 was healthy control and administered orally with $10 \mathrm{ml} / \mathrm{kg}$ of DW. Group $2-6$ were administered orally by gavage with $10 \mathrm{ml} / \mathrm{kg}$ of $50 \%(\mathrm{v} / \mathrm{v})$ ethanol for 14 consecutive days followed by DW, silymarin $(10 \mathrm{mg} / \mathrm{kg})$, or extracts $(50$, 100 , and $200 \mathrm{mg} / \mathrm{kg}$ ), respectively by oral gavage once a day for 7 consecutive days. At the end of the experiment, mouse blood was collected by cardiac puncture for determination of liver function. Additionally, the body weight of each mice in these groups was also measured. 


\section{Determination of liver injury}

Mouse blood was collected by cardiac puncture into heparinized vacuum tubes. Centrifugation was subsequently performed at $1,500 \mathrm{~g}$ for $10 \mathrm{~min}$, and the resulting supernatant (plasma) was separated for determination of liver injury. The liver enzymes, namely plasma aspartate aminotransferase (AST), alanine aminotransferase (ALT), gamma-glutamyl transferase (GGT) and alkaline phosphatase (ALP) levels, were measured by using Cobas c 311 Clinical Chemistry Automated Analyzer.

\section{Statistics}

All the results were presented as mean \pm standard error of mean (SEM) using GraphPad Prism (GraphPad Software version 5.01, Inc., USA). Data were analyzed by using 1-way ANOVA followed by Tukey's post-hoc test at the $95 \%$ confidence level.

\section{Results and discussion}

Acute toxicity of $\boldsymbol{A}$. ascalonicum extract in mice

In this study, the effect of aqueous crude extract of $A$. ascalonicum bulbs on ethanol-induced liver injury in mice was carried out. Hence, the acute toxicity of the extract in mice was performed before the main investigation. The extract administered orally by gavage in a single dose of $2,000 \mathrm{mg} / \mathrm{kg}$ did not show any indication of physical or behavioral changes such as hair erection, reduction in feeding and motor activities, weight loss, lacrimation, diarrhea, or depression within the monitoring period. No mortality occurred within the observation period of 21 days. Additionally, $2,000 \mathrm{mg} / \mathrm{kg}$ of the extract had shown no significant deviation in liver enzyme activities namely AST, ALT, GGT, and ALP when compared between healthy and extract treated groups (Figure 1). The lethal dose (LD50) of $A$. ascalonicum extract was estimated to be higher than $2,000 \mathrm{mg} / \mathrm{kg}$. Therefore, if a test compound has a LD50 higher than 3 times the minimum effective dose $(100 \mathrm{mg} / \mathrm{kg})$, it can be considered safe and is good candidate for further studies according to the OECD (Organization for Economic Cooperation and Development) guideline [23].

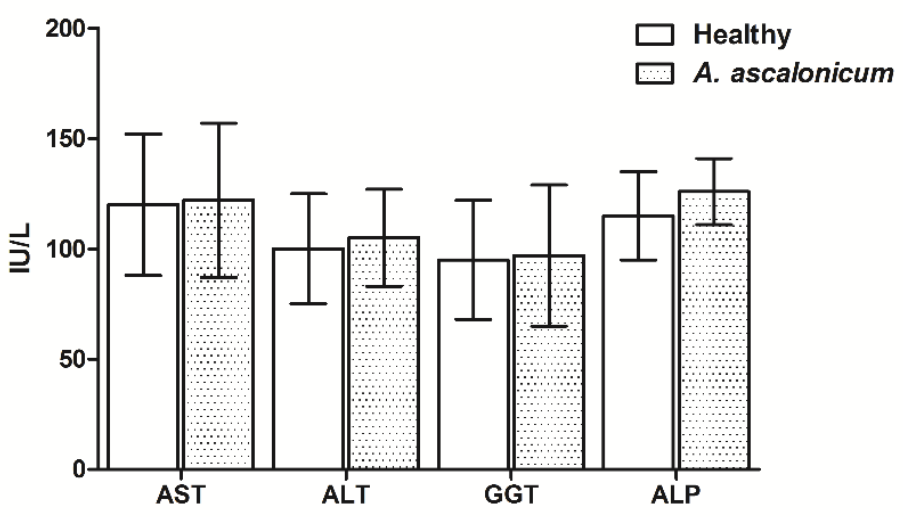

Figure 1 Effect of aqueous crude extract of $A$. ascalonicum bulbs on liver injury. Groups of mice were administered orally by gavage with a single dose of $2,000 \mathrm{mg} / \mathrm{kg}$ of extract once a day for 7 consecutive days. Liver enzyme activities including AST, ALT, GGT, and ALP levels were measured. Normal mice were given only DW and acted as healthy control. The results were expressed as mean $\pm \mathrm{SEM}$. 


\section{Effect of $A$. ascalonicum extract on ethanol-induced liver injury in mice}

After 14 days of ethanol administration, AST, ALT, GGT, and ALP levels significantly increased, compared to healthy group (Figure 2; $<<0.001$ ), which indicated ethanol-induced liver injury in mice. Interestingly, ethanol-induced increase in liver enzymes was improved by $A$. ascalonicum extract supplementation. AST, ALT, GGT, and ALP are sensitive indicators of alcohol-induced liver injury and are the most important parameters in routine clinical liver function tests. The results indicated the increase of these liver enzyme among alcohol-induced mice, and that the extract significantly ameliorated enzymatic activities at the doses of 100 and $200 \mathrm{mg} / \mathrm{kg}(\mathrm{p}<0.05)$. These mentioned doses of the extract brought back these liver enzymes to normal levels.

It has been reported that oxidative stress by ethanol induction might play a critical role in the mechanisms leading to ethanol-induced liver injury [7]. During ethanol consumption, the generation of oxidative stress through excess reactive oxygen species (ROS) produced by CYP2E1 and malondialdehyde (MDA) with decrease mitochondrial glutathione (GSH) and superoxide dismutase (SOD) levels can cause tissue damage in liver [24,25]. In addition, this oxidative damage induced mitochondrial dysfunction and cell apoptosis [26]. In addition to oxidative stress, NF- $\kappa \mathrm{B}$ and inflammation have been reported to play a key role in the pathogenesis and are related to pathological liver changes of ethanol-induced liver injury [27,28]. From our results, the A. ascalonicum extract presented hepatoprotective properties against ethanol-induced liver injury in mice. This property of the plant might be due to the presence of active compounds in this extract. Basically, quercetin and allicin have been reported to be active compounds of $A$. ascalonicum extract [20]. Quercetin has been described to have hepatoprotective property against ethanol-induced liver injury through antioxidant, antiinflammation, down-regulation of CYP2E1 and CYP3A, and increase glutathione levels [29-33]. Moreover, it has been reported that allicin has effectively shown hepatoprotective effect on ethanolinduced liver injury, which is related to its selective effect on the glutathione-related enzyme system [34]. Therefore, hepatoprotective activity observed in the aqueous crude extract of $A$. ascalonicum bulbs could have resulted from single compound or a combination of the above active compounds. However, at a comparatively low dose $(50 \mathrm{mg} / \mathrm{kg})$, the extract has no ability to significantly decrease liver enzyme activities. This could be due to the presence of active compounds at low level whose activity might not be detected at the lower dose.

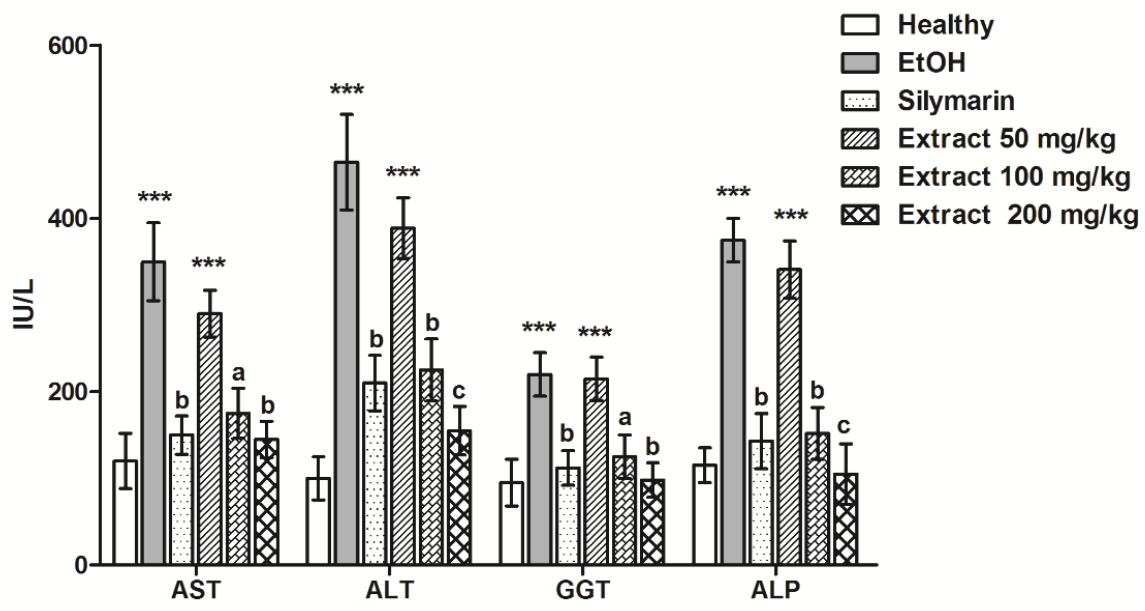

Figure 2 Effect of aqueous crude extract of $A$. ascalonicum bulbs on ethanol-induced liver injury in mice. Groups of mice were administered with $50 \%(\mathrm{v} / \mathrm{v})$ ethanol for 14 consecutive days followed by treatment with silymarin $(10 \mathrm{mg} / \mathrm{kg})$, and extracts $(50,100$, and $200 \mathrm{mg} / \mathrm{kg})$, by oral gavage once a day for 7 consecutive days. Liver enzyme activities namely AST, ALT, GGT, and ALP were measured. Normal mice were given only DW and acted as healthy control. The results were expressed as mean \pm SEM. *** $\mathrm{p}<0.001$, compared to healthy group. ${ }^{\mathrm{a}} \mathrm{p}<0.05,{ }^{\mathrm{b}} \mathrm{p}<0.01$, and ${ }^{\mathrm{c}} \mathrm{p}<0.001$, compared to ethanol treated group. EtOH; ethanol. 
Moreover, body weight loss was observed in ethanol treated group with significant $(\mathrm{p}<0.05)$ as compared to health control. Interestingly, mice administered with 100 and $200 \mathrm{mg} / \mathrm{kg}$ of $A$. ascalonicum extract showed dose-dependent protective effect on body weight loss (Figure 3). This might be due to the hepatoprotective effect of active compounds in the extract against ethanol-induced liver injury in mice.

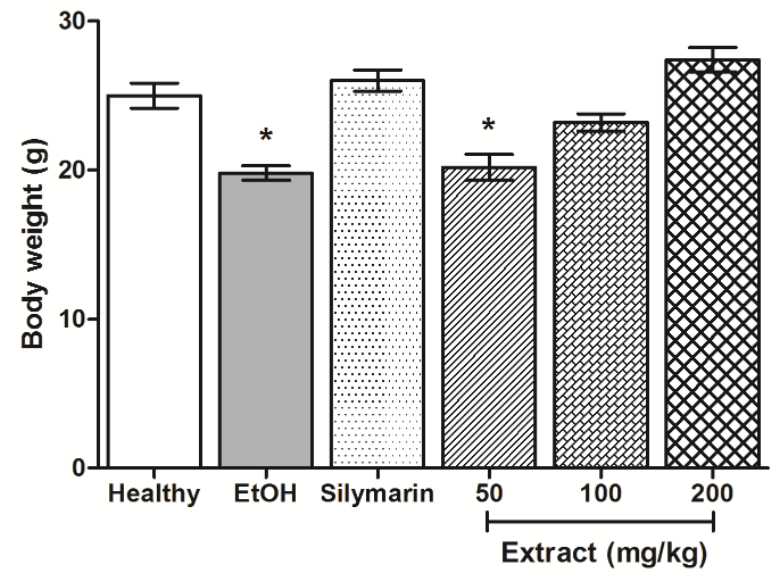

Figure 3 Effect of aqueous crude extract of $A$. ascalonicum bulbs on body weight of ethanol-induced liver injury in mice. Groups of mice were administered with $50 \%(\mathrm{v} / \mathrm{v})$ ethanol for 14 consecutive days followed by treatment with silymarin $(10 \mathrm{mg} / \mathrm{kg})$, and extracts $(50,100$, and $200 \mathrm{mg} / \mathrm{kg})$, by oral gavage once a day for 7 consecutive days. Body weight of mice in these groups were measured. Normal mice were given only DW and acted as healthy control. The results were expressed as mean $\pm \mathrm{SEM}$. ${ }^{*} \mathrm{p}<0.05$, compared to healthy group. EtOH; ethanol.

\section{Conclusions}

From this study, it could be concluded that the aqueous crude extract of $A$. ascalonicum bulbs showed hepatoprotective effect on ethanol-induced liver injury in mice with lack of toxicity. However, further studies are recommended to confirm the mode of actions as well as safety profiles of the extract. These results strongly emphasize that aqueous crude extract of $A$. ascalonicum bulbs appear to be an attractive complementary drug candidate for the treatment and prevention of ethanol-induced liver injury.

\section{Acknowledgements}

The authors would like to acknowledge the Faculty of Medical Technology, Western University for allowing the material assistance for this study. We also wish to special thank Prof. Dr. Somdet Srichairatanakool from Chiang Mai University and Dr. Chairat Uthaipibull from BIOTEC, NSTDA for their valuable discussions and for providing logistic support.

\section{References}

[1] PD Axley, CT Richardson and AK Singal. Epidemiology of alcohol consumption and societal burden of alcoholism and alcoholic liver disease. Clin. Liver Dis. 2019; 23, 39-50.

[2] M Thavorncharoensap, Y Teerawattananon, J Yothasamut, C Lertpitakpong, K Thitiboonsuwan, $\mathrm{P}$ Neramitpitagkul and U Chaikledkaew. The economic costs of alcohol consumption in Thailand, 2006. BMC Public Health 2010; 10, 323.

[3] T Thamarangsi. Thailand: Alcohol today. Addiction 2006; 101, 783-7. 
[4] M Wakabayashi, R McKetin, C Banwell, V Yiengprugsawan, M Kelly, SA Seubsman, H Iso, A Sleigh and Thai Cohort Study Team. Alcohol consumption patterns in Thailand and their relationship with non-communicable disease. BMC Public Health 2015; 15, 1297.

[5] E Albano. Alcohol, oxidative stress and free radical damage. Proc. Nutr. Soc. 2006; 65, 278-90.

[6] CS Lieber. Alcoholic fatty liver: Its pathogenesis and mechanism of progression to inflammation and fibrosis. Alcohol 2004; 34, 9-19.

[7] S Li, HY Tan, N Wang, ZJ Zhang, L Lao, CW Wong and Y Feng. The role of oxidative stress and antioxidants in liver diseases. Int. J. Mol. Sci. 2015; 16, 26087-124.

[8] E Ceni, T Mello and A Galli. Pathogenesis of alcoholic liver disease: Role of oxidative metabolism. World J. Gastroenterol. 2014; 20, 17756-72.

[9] PK Eagon. Alcoholic liver injury: Influence of gender and hormones. World J. Gastroenterol. 2010; 16, 1377-84.

[10] F Stickel, HK Seitz, EG Hahn and D Schuppan. Alcoholic liver disease-established treatment and new therapeutic approaches. Zeitschrift für Gastroenterol. 2003; 41, 333-42.

[11] H Yao, YJ Qiao, YL Zhao, XF Tao, LN Xu, LH Yin, Y Qi and JY Peng. Herbal medicines and nonalcoholic fatty liver disease. World J. Gastroenterol. 2016; 22, 6890-905.

[12] N Shang, A Saleem, L Musallam, B Walshe-Roussel, A Badawi, A Cuerrier, JT Arnason and PS Haddad. Novel approach to identify potential bioactive plant metabolites: Pharmacological and metabolomics analyses of ethanol and hot water extracts of several Canadian medicinal plants of the Cree of Eeyou Istchee. PloS One 2015; 10, e0135721.

[13] RB Ding, K Tian, LL Huang, CW He, Y Jiang, YT Wang and JB Wan. Herbal medicines for the prevention of alcoholic liver disease: A review. J. Ethnopharmacol. 2012; 144, 457-65.

[14] J Sharifi-Rad, D Mnayer, G Tabanelli, ZZ Stojanovic-Radic, M Sharifi-Rad, Z Yousaf, L Vallone, WN Setzer and M Iriti. Plants of the genus Allium as antibacterial agents: From tradition to pharmacy. Cell. Mol. Biol. 2016; 62:57-68.

[15] HR Mohammadi-Motlagh, A Mostafaie and K Mansouri. Anticancer and anti-inflammatory activities of shallot (Allium ascalonicum) extract. Arch. Med. Sci. 2011; 7, 38-44.

[16] S Saenthaweesuk, R Jitvaropas, N Somparn and A Thuppia. An investigation of antimicrobial and wound healing potential of Allium ascalonicum Linn. J. Med. Assoc. Thai. 2015; 98, S22-7.

[17] D Mnayer, AS Fabiano-Tixier, E Petitcolas, T Hamieh, N Nehme, C Ferrant, X Fernandez and F Chemat. Chemical composition, antibacterial and antioxidant activities of six essentials oils from the Alliaceae family. Molecules 2014; 19, 20034-53.

[18] MF Sani, SM Kouhsari and L Moradabadi. Effects of three medicinal plants extracts in experimental diabetes: Antioxidant enzymes activities and plasma lipids profiles in comparison with metformin. Iran J. Pharm. Res. 2012; 11, 897-903.

[19] O Wongmekiat, $\mathrm{N}$ Leelarugrayub and $\mathrm{K}$ Thamprasert. Beneficial effect of shallot (Allium ascalonicum L.) extract on cyclosporine nephrotoxicity in rats. Food Chem. Toxicol. 2008; 46, 1844-50.

[20] E Fattorusso, M Iorizzi, V Lanzotti and O Taglialatela-Scafati. Chemical composition of shallot (Allium ascalonicum Hort.). J. Agric. Food Chem. 2002; 50, 5686-90.

[21] MJ Guan, N Zhao, KQ Xie and T Zeng. Hepatoprotective effects of garlic against ethanol-induced liver injury: A mini-review. Food Chem. Toxicol. 2018; 111, 467-73.

[22] D Lorke. A new approach to practical acute toxicity testing. Arch. Toxicol. 1983; 54, 275-87.

[23] EM Smith. The organisation for economic cooperation and development (OECD) and chemical safety. IARC Sci. Publ. 1980; 27, 361-4.

[24] TM Leung and Y Lu. Alcoholic liver disease: From CYP2E1 to CYP2A5. Curr. Mol. Pharmacol. 2017; 10, 172-8.

[25] KH Han, N Hashimoto and M Fukushima. Relationships among alcoholic liver disease, antioxidants, and antioxidant enzymes. World J. Gastroenterol. 2016; 22, 37-49.

[26] BA Potz, IJ Lawandy, RT Clements and FW Sellke. Alcohol modulates autophagy and apoptosis in pig liver tissue. J. Surg. Res. 2016; 203, 154-62. 
[27] B Relja, R Weber, M Maraslioglu, N Wagner, T Borsello, C Jobin, I Marzi and M Lehnert. Differential relevance of NF-kappaB and JNK in the pathophysiology of hemorrhage/resususcitation-induced liver injury after chronic ethanol feeding. PloS One 2015; 10, e0137875.

[28] M Maraslioglu, R Weber, S Korff, C Blattner, C Nauck, D Henrich, C Jobin, I Marzi and M Lehnert. Activation of NF-kappaB after chronic ethanol intake and haemorrhagic shock/resuscitation in mice. Br. J. Pharmacol. 2013; 170, 506-18.

[29] SK Bedada and P Neerati. The effect of quercetin on the pharmacokinetics of chlorzoxazone, a CYP2E1 substrate, in healthy subjects. Eur. J. Clin. Pharmacol. 2018; 74, 91-7.

[30] X Chen. Protective effects of quercetin on liver injury induced by ethanol. Pharmacogn. Mag. 2010; 6, $135-41$.

[31] A Vidhya and M Indira. Protective effect of quercetin in the regression of ethanol-induced hepatotoxicity. Indian J. Pharm. Sci. 2009; 71, 527-32.

[32] J Ostlund, V Zlabek and G Zamaratskaia. In vitro inhibition of human CYP2E1 and CYP3A by quercetin and myricetin in hepatic microsomes is not gender dependent. Toxicology 2017; 381, 108.

[33] Y Tang, H Tian, Y Shi, C Gao, M Xing, W Yang, W Bao, D Wang, L Liu and P Yao. Quercetin suppressed CYP2E1-dependent ethanol hepatotoxicity via depleting heme pool and releasing CO. Phytomedicine 2013; 20, 699-704.

[34] H Wang, R Peng, R Kong and H Zeng. Effect of allicin on ethanol-induced hepatotoxicity in mice. J. Hyg. Res. 1998; 27, 415-7. 